\title{
A COR NA FOTOGRAFIA EM PRETO-E-BRANCO COMO UMA FLAGRANTE MANIFESTAÇÃO CULTURAL ${ }^{1}$
}

Luciana Martha Silveira ${ }^{2}$

Nosso mundo visível é colorido e por isso a cor participa de diversas formas na nossa percepção. Neste contexto, a cor não se restringe ao sentido poético, nos auxiliando também a perceber texturas, bordas, temperaturas e distâncias, além dos significados atribuídos culturalmente aos objetos.

A percepção visual cromática é construída durante toda a vida de um indivíduo (Gibson, 1974), sendo a cor uma das principais características agregadas aos objetos percebidos. Assim, atribuímos culturalmente a uma imagem em preto-e-branco o sentido de uma imagem incolor, sem vida ou sem emoção, enfim uma imagem que não despertaria a percepção cromática. Colaborando com essa idéia, a complexidade do processo de apreensão do nosso mundo físico visual não nos permite desprovê-lo conscientemente da cor apenas através dos olhos, ou seja, para tornar o nosso mundo colorido um mundo em preto-e-branco, necessitamos da nossa imaginação ou de aparelhos como uma câmera fotográfica ou vídeo.

As imagens em preto-e-branco que povoam o nosso mundo visual são produzidas por meio de várias mediações como a pintura, a gravura, o

1 Este texto foi produzido com o apoio do CNPQ e faz parte da pesquisa em curso intitulado “

2 Doutora em Comunicação e Semiótica, professora e pesquisadora do Programa de Pós-Graduação em Tecnologia (PPGTE) da UTFPR 
vídeo, o cinema, a computação gráfica ou a fotografia. Sabemos, através da história da arte, que é incorreto afirmar que não possuem vida, somente por não terem sido construídas a partir do grande leque de opções cromáticas (Janson, 1996).

Guernica (figura 1), por exemplo, não é uma imagem sem vida ou sem sentimento por não possuir outras cores além do branco, do preto e dos cinzas intermediários.

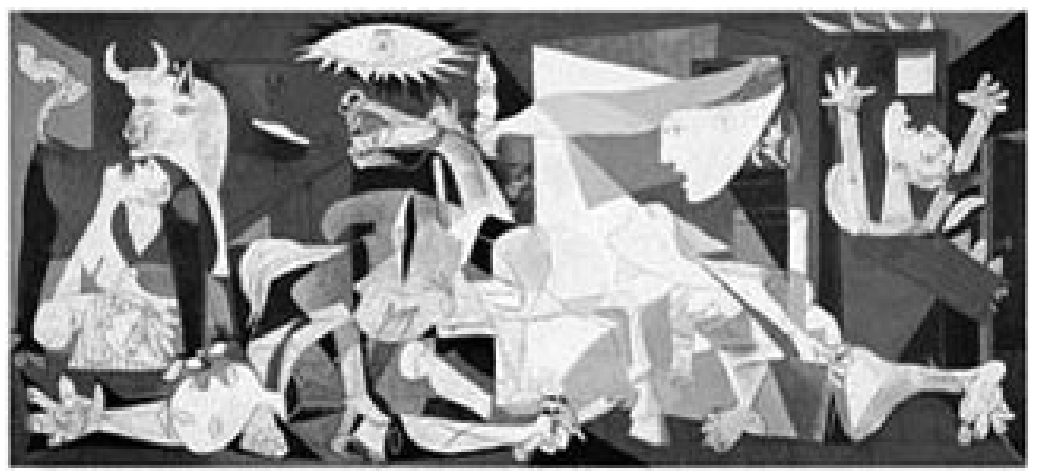

Figura 1 - Guernica, de Pablo Picasso, 3.50 X 7.82m, 1937.

A diminuição nas opções cromáticas não impediu Picasso de representar uma cena altamente dramática, composta por uma série de imagens poderosas, com pessoas massacradas e a agonia da guerra numa visão profética e impressionante da desgraça.

Isso também acontece numa xilogravura, geralmente construída somente com as cores preto e branco. O artista suéco Felix Vallotton, com poucos ataques de buris na madeira, consegue passar, como mostra a figura 2, muitas das sensações de luminosidade de uma cena, somadas à postura de um violinista e sua concentração em tocar o instrumento, o armário decorado e brilhante, o fogo iluminando a cena da esquerda para a direita e até a escultura frágil em cima da lareira. Tudo isso apenas com preto e branco. Devemos dizer que esta cena não possui poesia por não possuir um grande leque de cores, ou ainda que perceberíamos mais detalhes se tivesse sido preenchida por outras cores além do branco e do preto? 


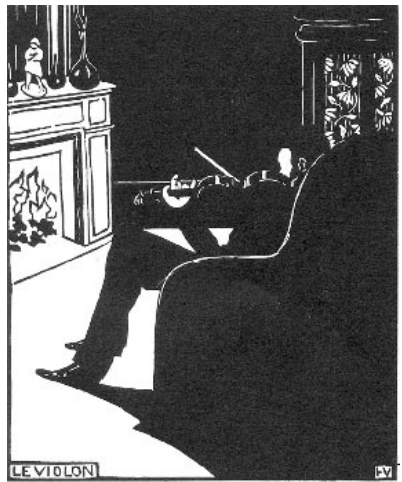

Figura 2 - O Violino, de Felix Vallotton, xilogravura, 224 X 180mm, 1896.

As imagens fotográficas em preto-e-branco também nos despertam as mais diversas sensações, que vão desde a evidência da estrutura ou do "esqueleto" das imagens, até a liberdade de cromatizá-las através da imaginação.

$\mathrm{Na}$ imagem a seguir (figura 3), temos um exemplo de fotografia que usa o branco, o preto e os cinzas para representar uma cena. É impossível não se deixar impressionar pela imagem do pintor em ação, capturada pela câmera de William Klein. Será que a presença física da cor nos causaria mais emoção?

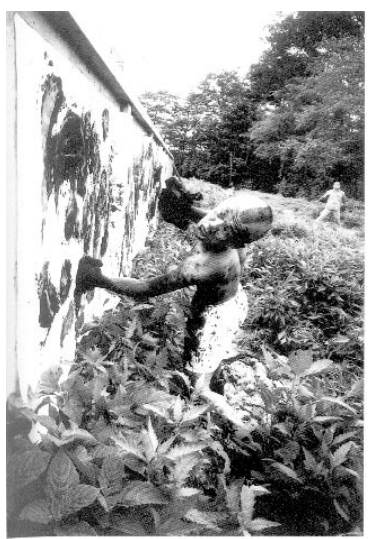

Figura 3 - Pintor de acção japonês, de William Klein, 1961. 
Longe de serem imagens sem vida, sem variedade ou sem sentido, as imagens em preto-e-branco fazem parte do mundo físico visual como "chaves" ou partes integrantes da construção perceptiva cromática em cada indivíduo, fazendo explodir cores subjetivas e particulares, sendo por isso muito mais brilhantes e misteriosas que as cores fisicamente fixadas nas imagens.

Cada ser humano constrói seu modo específico de ver e interpretar a cor nos objetos. Sabemos que esta construção envolve também uma parte coletiva que chamamos cultura. Portanto, cada indivíduo faz de seu mundo visual um mundo particular em cores (Gibson, 1974), construído culturalmente.

Sendo o universo dessas imagens uma variedade muito grande de suportes e técnicas de linguagem e na impossibilidade de uma discussão suficientemente abrangente num único trabalho, um recorte se faz necessário. Este recorte será a imagem fotográfica, que nos servirá de suporte à discussão: a percepção cromática nas imagens fotográficas em preto-e-branco.

A imagem fotográfica em preto-e-branco não pode ser considerada como uma imagem "sem cor", mas sim uma imagem "colorida". As discussões em torno da imagem fotográfica em preto-e-branco, geralmente, se voltam aos impactos tecnológicos na produção da imagem, a comparação com a pintura, a interferência do fotógrafo e do dispositivo no processo de captura da imagem, não se detendo na sua interpretação visual cromática. Desta atitude decorre a idéia de que a imagem fotográfica em preto-ebranco é uma imagem "sem cor".

Por outro lado, a teoria da cor é uma teoria interdisciplinar, que pode ser aplicada em inúmeras situações, prevendo os múltiplos aspectos da percepção visual cromática, interagindo na interpretação do nosso mundo físico visual.

Relações entre a teoria perceptiva cromática e as mais inusitadas áreas do conhecimento começam a ser desenvolvidas. Um exemplo bastante difundido através dos neurologistas Oliver Sacks e António Damásio é a aplicação da teoria da percepção cromática nos casos de acromatopsia cerebral adquirida (Sacks, 1995) (Damásio et al., 1980). 
Reforçando o fato de que a percepção cromática compartilha tanto da modalidade visual quanto da sensória, o caso do pintor daltônico (Sacks, 1995) descreve a súbita lesão no dispositivo óptico fisiológico visual do Sr. I. e evidencia o complexo composto da percepção cromática, principalmente na sua adaptação. Reorganizando o seu mundo a partir da acromatopsia cerebral adquirida, o Sr. I. reforça a idéia de que a percepção é um todo e que suas partes não podem ser consideradas separadamente.

Assim como a cor se reestrutura no mundo visual do pintor daltônico com um suposto reforço na forma e na textura, a fotografia em preto-ebranco tem a presença da cor também de outras maneiras que não as convencionais.

A imagem em preto-e-branco pertence ao universo cromático dos indivíduos e por isso deve ter a percepção cromática integrada aos seus estudos de maneira geral.

Para discutir esta idéia, conceitos serão reunidos a partir da teoria da cor, aparentemente não correlacionados, definindo dois resultados intermediários necessários para a demonstração da percepção cromática na imagem fotográfica em preto-e-branco:

1. o branco, o preto e os cinzas são cores;

2. os objetos reconhecidos na imagem são complementados cromaticamente.

Primeiramente, o branco, o preto e os cinzas devem ser considerados como cores, isto é, são tão cores como qualquer outra do espectro. Depois, considera-se que existe a complementação cromática dos objetos reconhecidos na imagem, isto é, traduções cromáticas são percebidas através do reconhecimento do objeto e da comparação desta percepção visual com a interpretação anterior deste mesmo objeto a partir da memória pessoal.

Estes dois fatos perceptivos são desenvolvidos com base na correlação entre arcabouços teóricos aparentemente diversos: a teoria da cor e a teoria da imagem fotográfica, proporcionando a formulação de nove situações, onde a presença da percepção cromática nas imagens fotográficas em pretoe-branco são flagradas. Estas situações são denominadas "eventos de cor", correspondendo a nove acontecimentos perceptivos cromáticos, flagrados 
no âmbito da percepção visual geral de uma imagem fotográfica em pretoe-branco, na união de um tipo de estímulo vindo da própria imagem e uma resposta cromática.

Deve-se salientar que limites precisos foram fixados para 0 desenvolvimento desta idéia. Dentre eles: o recorte na imagem fotográfica indica somente esta linguagem como suporte para o desenvolvimento da tese, limitando-nos ainda a discutir a imagem fotográfica e não o processo fotográfico; não discutiremos a escolha cromática de cada indivíduo, isto é, a cor determinada por cada um nas paletas de complementação cromática. O que interessa para este trabalho é o ato da complementação cromática da imagem fotográfica em preto-e-branco e não a cor particularmente determinada para a mesma.

O objetivo maior deste trabalho é provocar um novo modo de "ver" a imagem fotográfica em preto-e-branco. A presença individual da percepção cromática neste tipo de imagem, nos força a admitir a sua complexidade.

\section{OS EVENTOS DE COR: UMA DEFINIÇÃO}

Situações nas quais a percepção cromática acontece na imagem fotográfica em preto-e-branco são denominadas eventos de cor. Um evento de cor é um acontecimento perceptivo cromático ou o ato de perceber a cor, flagrado no âmbito da percepção visual geral de uma imagem fotográfica em preto-e-branco.

$\mathrm{O}$ estímulo vindo dos elementos formais constitutivos da imagem provoca uma resposta. A cada estímulo temos uma resposta diferente e quando este composto resulta em percepção cromática, é identificado como um evento de cor. O evento de cor não é o estímulo e nem a resposta perceptiva isolados, mas sim o processo de perceber as cores na imagem fotográfica em preto-e-branco, onde o estímulo e a resposta interagem simultaneamente.

Para que identifiquemos um evento de cor, devemos reconhecer um estímulo a partir da imagem fotográfica em preto-e-branco, capaz de provocar uma possível resposta perceptiva cromática no observador. Sendo este um composto subjetivo e abstrato, a cada estímulo teremos 
uma resposta cromática diferente, e sendo assim, eventos de cor também diferentes.

Delimitaremos aqui nove eventos de cor identificados no composto perceptivo visual de uma imagem fotográfica em preto-e-branco. Os elementos diferenciadores entre os nove eventos de cor serão os diversos tipos de estímulos extraídos da própria imagem e de respostas perceptivas cromáticas provocadas por eles no observador.

Numa imagem fotográfica em preto-e-branco, podemos reconhecer vários de seus elementos formais constitutivos, que podem ser considerados estímulos para a ocorrência da percepção cromática e, sendo assim, diferenciadores para os nove eventos de cor.

$\mathrm{Na}$ figura 4, por exemplo, podemos identificar os objetos "céu", "montanhas com neve", "árvores”, "folhagens" e "lago", através dos contrastes entre o branco, o preto e os cinzas e suas diferenças de luminosidades.

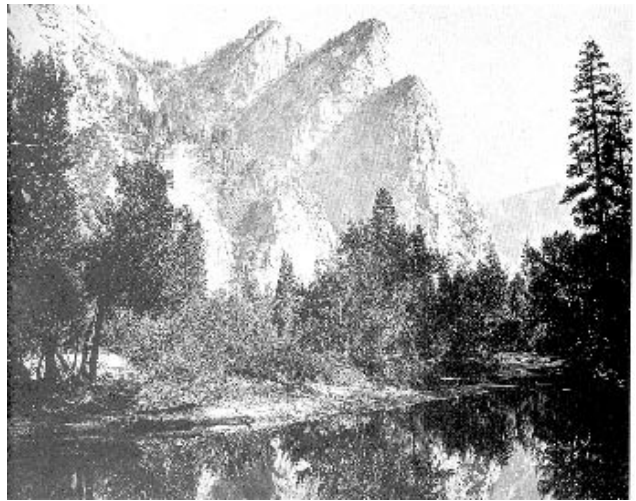

Figura 4 - Os três irmãos, Vale Yosemite, de Carleton E. Watkins, 1865 - 1866.

Estes elementos formais, ou objetos, identificados na imagem 3, são estímulos perceptivos extraídos da própria imagem, e possivelmente vão gerar respostas cromáticas para estes mesmos objetos.

As respostas poderão se dar de muitas maneiras, nem sempre mensuráveis, mas aqui trataremos de duas maneiras principais: considerando o branco, o preto e os cinzas da imagem fotográfica tão cores quanto o 
vermelho, o verde e o amarelo, ou através da complementação cromática quando o branco, o preto e os cinzas da imagem são "traduções" de outras cores e por isso estimulam a produção de um intervalo cromático (paleta) individual, isto é, que se diferencia de pessoa para pessoa.

$\mathrm{Na}$ figura 5 podemos identificar outros estímulos à percepção cromática, como a folhagem que serve de cenário, o enfeite do cabelo, a pele negra da moça e seus olhos.

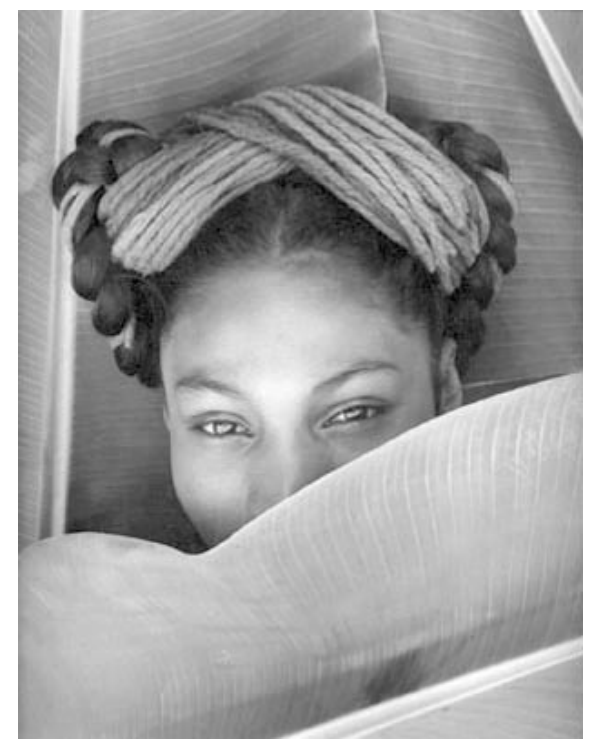

Figura 5 - Nievis, de Fritz Henle, 1943.

Ainda nesta figura, percebemos mutações cromáticas que ocorrem nas nervuras das folhas e no enfeite do cabelo, provocando outros cinzas. Todos estes elementos são estímulos para a percepção cromática, provocando respostas cromáticas no observador. A cada estímulo temos um tipo de reação (resposta), e a cada conjunto estímulo-resposta um tipo de evento de cor.

Podem também ser reconhecidos, numa imagem fotográfica em preto-e-branco, os objetos que remetem a relações temporais, como o chapéu que a moça está usando na figura 6 . 


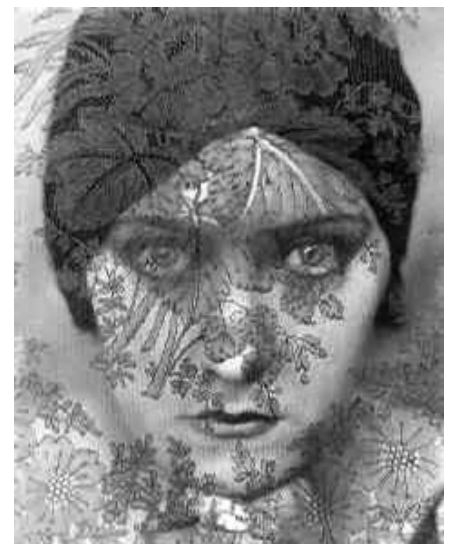

Figura 6 - Gloria Swanson, de Edward Steichen, 1926

Na imagem 6 também podemos perceber como um estímulo a textura do tecido que cobre o rosto. O material de que é feito o tecido, a renda transparente, é dado através do contraste entre o branco, o preto e os cinzas. A luminosidade diversa entre os cinzas também leva-nos a perceber os olhos claros e os lábios pintados da moça, outros objetos que servirão como estímulo à percepção cromática nesta imagem.

Outros elementos formais que podem ser percebidos numa imagem fotográfica em preto-e-branco são áreas extensas uniformemente preenchidas, como mostra a figura 7 . Estas áreas são anteparos perfeitos para fenômenos como o da cor inexistente.

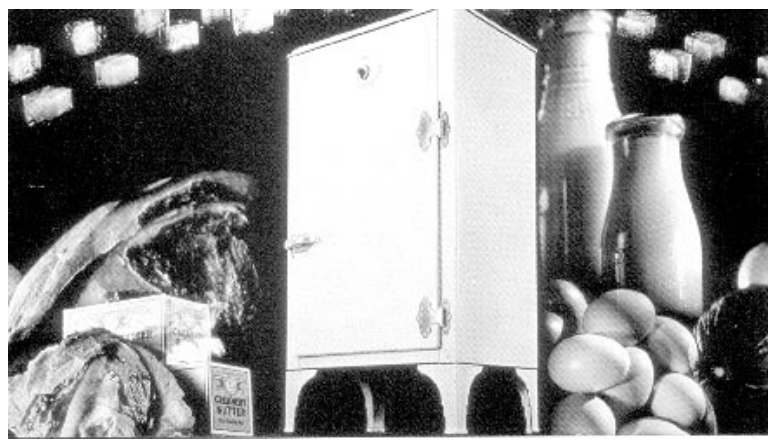

Figura 7 - A Caixa de gelo, de Grancel Fitz, 1928. 
Além disso, podemos identificar nesta imagem objetos extremamente comuns ao nosso cotidiano, como ovos, geladeira, litros de leite, juntamente com outros objetos que não conseguimos identificar, dos quais podemos, através da diferença de luminosidades, perceber as formas. A geladeira e os litros de leite, além de simplesmente serem reconhecidos, mantêm estreita relação com um tempo passado. $\mathrm{O}$ design da geladeira e do litro de leite é percebido como antigo em comparação ao design da geladeira e da embalagem de leite atuais. Estes elementos formais percebidos, podem ser considerados estímulos à percepção das cores e veremos como provocam a resposta da complementação cromática.

Os elementos formais da imagem fotográfica em preto-e-branco que vimos nestas figuras são os estímulos da percepção cromática e provocam diferentes respostas. A este processo chamamos eventos de cor. Independentemente do tipo de estímulo ou da paleta individualmente determinada como resposta perceptiva cromática, o evento de cor é o ato da percepção cromática na fotografia em preto-e-branco.

A denominação evento de cor foi escolhida aqui justamente pelo significado abstrato da palavra "evento", que nos remete aos aspectos subjetivos da percepção. Tanto a percepção visual cromática como os eventos de cor são subjetivos e abstratos, de difícil acesso objetivo para descrições e análises. Porém, eles podem ser delimitados através de exemplificações de estímulos e respostas no âmbito da percepção cromática, tornando-se suficientemente pontuais para serem descritos e analisados.

Cabe destacar que as paletas "percebidas" nos eventos são construídas num composto inconsciente, parte coletivo, parte individual, como mostra a teoria perceptiva de Gibson (1974). Os significados agregados aos objetos, dentre eles a cor, são apreendidos dentro do repertório de experiências do indivíduo, o que depende diretamente da memória e difere de um indivíduo para outro. Cada ser humano apreende o significado cromático do mundo visual sob o embasamento de sua educação e cultura próprias, de onde se pode concluir que $\mathrm{o}$ significado é atribuído às cores em parte pela cultura $\mathrm{e}$ em parte pela experiência exclusiva da elaboração individual.

Mais uma vez cabe dizer que, muito mais que um único estímulo ou uma única resposta em forma de um intervalo cromático (paleta), o evento 
de cor é o acontecimento da percepção cromática na imagem fotográfica em preto-e-branco quando da junção de um tipo de estímulo com um tipo de resposta cromática, sendo mais amplo que qualquer escolha de paletas.

Inicialmente, podemos separar os eventos de cor em estímulos e respostas diferenciados entre si, porém, eles não possuem limites visíveis. Um objeto reconhecido numa imagem fotográfica em preto-e-branco pode ser estímulo para mais de um evento simultaneamente.

Os nove eventos de cor estão divididos em dois momentos: a sensação cromática e a percepção cromática. Os três primeiros eventos estão fundamentados no conceito de que "o branco, o preto e os cinzas são cores" e os outros seis eventos estão fundamentados no conceito da "complementação cromática".

O primeiro momento está ligado aos aspectos físicos da cor, isto é, dá-se ênfase à sensação física que acontece no nível dos olhos, onde ainda não há a interação com os aspectos psicológicos e culturais da cor. No âmbito da sensação cromática, consideramos o branco, o preto e os cinzas como únicos elementos cromáticos da imagem fotográfica em pretoe-branco.

O segundo momento na descrição dos eventos de cor na fotografia em preto-e-branco é o da percepção cromática. A percepção visual cromática está no nível da interpretação do cérebro para as imagens capturadas pelos olhos. No cérebro há a interação entre os aspectos físicos, fisiológicos, psicológicos e culturais da percepção cromática, fazendo dela um composto altamente complexo.

No âmbito dos últimos seis eventos de cor, o branco, o preto e os cinzas da imagem fotográfica em preto-e-branco, além de cores eles mesmos, serão tratados como "traduções" de outras cores. Por este motivo, esses eventos se fundamentam no conceito de complementação cromática, isto é, no ato inconsciente e individual de complementar cromaticamente os elementos formais reconhecidos na imagem fotográfica "sem cor". Os elementos formais que servirão de estímulos aos eventos de cor do segundo momento são: os objetos tidos como possuidores de matiz única, os objetos de cenário, os objetos que remetem a relações temporais, os objetos sem significado cromático e os fenômenos de contrastes. 
Mesmo dividindo os eventos em dois momentos objetivos, denominando-os entre os estímulos e respostas da percepção cromática, sabemos que continuam sendo subjetivos. O processo de entender 0 branco, preto e cinzas como cores e como "tradução" de outras cores, fazendo a complementação cromática dos objetos reconhecidos numa imagem fotográfica em preto-e-branco, é abstrato e impalpável. Apesar disso, tenta-se colocá-los na forma mais objetiva possível, analisando a sua ocorrência em imagens fotográficas em preto-e-branco.

\section{QUANDO O BRANCO, O PRETO E OS CINZAS SÃO CORES}

O primeiro momento na divisão dos eventos de cor depende da conceitualização do branco, do preto e dos cinzas e suas funções na geração de significados, a partir das imagens. Os três primeiros eventos de cor que serão aqui enunciados colocam o branco, o preto e os cinzas da imagem na condição de "cores", bem como todas as outras cores do espectro. Nesta condição, portanto, o branco, o preto e os cinzas são cores por elas mesmas na percepção da imagem.

Tradicionalmente, os aspectos físicos da teoria da cor consideram que seja cor somente aquela que possui o que se chama matiz. Por esta definição, todas as cores do espectro, exceto o branco, o preto e os cinzas, possuem matiz definida, e são por isso denominadas "cores". A definição de cor fundamentada na presença ou não de um matiz é estanque e específica, não permitindo a interação com outras visões como, por exemplo, a dos pintores. O branco, neste caso, deve ser considerado como uma reunião criativa de vários matizes e não como uma simples somatória de partes. $\mathrm{O}$ preto, por sua vez, não é uma simples absorção de todos os matizes, e sim também uma reunião complexa de partes. Tendo isto em vista, podemos considerar branco e preto como possuidores de matizes, portanto, os cinzas intermediários também o são.

O "primeiro evento de cor" é a percepção de elementos componentes da imagem fotográfica em $\mathrm{p} / \mathrm{b}$, através do grau de contraste entre o branco, o preto e os cinzas. $\mathrm{O}$ contraste gera a percepção da textura, que por sua vez colabora na percepção do material, do tamanho e da estrutura dos objetos retratados. Algumas cores são construídas além da sensibilização 
fisiológica dos cones. São elas a cor metálica, a cor transparente ou a cor translúcida, que são percebidas na fotografia em $\mathrm{p} / \mathrm{b}$ em interação com a percepção de texturas, através dos contrastes.

$\mathrm{O}$ "segundo evento de cor" fundamentou-se no conceito das mutações cromáticas, ou seja, nas alterações da percepção visual cromática de uma ou mais cores, em decorrência da presença influente de outras. Segundo a definição de mutação cromática, saturando-se a retina com uma cor indutora, a sua cor complementar influencia a percepção de todas as outras cores para onde se dirige o olhar e assim sucessivamente. No caso de uma imagem com cores sem a presença de matizes, mas somente de valores, as cores indutoras provocam outras cores que também apresentam somente variação de valor e não de matiz. Assim sendo, numa imagem fotográfica em $\mathrm{p} / \mathrm{b}$ as cores indutoras (branco, preto e cinzas) provocam uma grande variedade de outros cinzas entre o branco e o preto.

O "terceiro evento de cor" foi fundamentado na teoria da cor inexistente, a qual trata das cores que aparecem fisicamente, baseadas na relatividade de absorção e reflexão, pela matéria, dos raios luminosos. As áreas brancas, pretas e cinzas da imagem fotográfica em $\mathrm{p} / \mathrm{b}$ servem como anteparo para a explosão de cores resultante da reflexão e/ou absorção de parte da luz incidente. Isso acontece porque nenhum corpo absorve ou reflete totalmente os raios luminosos. Para percebermos brancos e pretos perfeitos, os raios da fonte luminosa incidente deveriam ser totalmente refletidos (no caso do branco) ou totalmente absorvidos (no caso do preto). Porém, no processo de absorção ou reflexão, há sempre a perda de raios, alterando o resultado perceptivo do branco, do preto e dos cinzas.

\section{QUANDO O BRANCO, O PRETO E OS CINZAS SÃO MAIS DO QUE CORES}

Trataremos aqui do segundo momento na divisão dos eventos de cor, onde o branco, o preto e os cinzas que compõem as cenas, além de serem vistos como cores eles mesmos, também podem ser vistos como traduções de outras cores. Na imagem fotográfica em $\mathrm{p} / \mathrm{b}$, as traduções cromáticas são percebidas através do reconhecimento do objeto e da comparação (em nível inconsciente) desta percepção visual com a interpretação anterior 
deste objeto a partir da memória pessoal. Quando, através da comparação, percebe-se a "falta" da cor, acontece o que chamamos "complementação cromática”.

A complementação cromática é o ato perceptivo visual individual, subjetivo, parte consciente e parte inconsciente, de complementar cromaticamente objetos reconhecidos em quaisquer imagens fotográficas em $\mathrm{p} / \mathrm{b}$. Ele acontece porque no processo de percepção cromática há a comparação entre os objetos reconhecidos nos vários tipos de imagens em $\mathrm{p} / \mathrm{b}$ e objetos guardados na memória, a partir do vasto conjunto imagético adquirido no ato interpretativo de "ver".

O conceito de complementação cromática está no nível da percepção cromática, isto é, considera a cor percebida em integração com a cultura, memória e o estado psicológico do observador. Depois de retomados conceitos da teoria da cor tais como "a teoria perceptiva de J. J. Gibson (Gibson, 1974)", "cor de memória (Bartleson, 1960)" e "constância cromática (Gibson, 1974)", podemos concluir que a cor é percebida e alocada na memória, num composto com os outros parâmetros de formação perceptiva de um objeto. Sendo assim, quando reconhecemos um objeto numa imagem fotográfica em $\mathrm{p} / \mathrm{b}$ (o estímulo), este será complementado cromaticamente (a resposta).

O reconhecimento do objeto e a delimitação de um intervalo de cor correspondente a ele são elementos obtidos através de "sugestões" que se encontram na própria imagem, que podem ser mapeadas a partir dos parâmetros de análise da cor de Albert Munsell (Caivano, 1995). De acordo com Munsell, uma cor é constituída por três variáveis de análise: matiz, valor e croma. Dadas estas três variáveis de análise, define-se um intervalo de cor. Retomando suas definições: Matiz é a característica que diferencia uma cor da outra: o azul do amarelo, o azul do vermelho, etc.; Valor é o grau de claridade ou de obscuridade contido numa cor; Croma é a qualidade de saturação de cada cor que indica seu grau de pureza.

As três variáveis de análise de Munsell (matiz, valor e croma) estão sugeridas na própria imagem fotográfica em $\mathrm{p} / \mathrm{b}$ e, a partir da sua junção, temos a indicação de um intervalo cromático determinado (paleta) para 
a ocorrência da complementação cromática. A variável matiz é dada pela forma do objeto, sugerida pelos contrastes entre o branco, o preto e os cinzas da imagem. A forma determina um tipo específico de objeto, que remete à interpretação a partir da memória e conseqüentemente ao seu significado cromático agregado. O matiz está ligado aos objetos na memória de cada indivíduo de forma pessoal e diferenciada.

A qualidade da cor (valor e croma) é dada pela luminosidade dos cinzas alocados em cada objeto da imagem, que remetem ao grau de claridade, obscuridade e saturação.

Os eventos de cor que serão abordados neste item fundamentamse na complementação cromática de objetos reconhecidos na imagem fotográfica em $\mathrm{p} / \mathrm{b}$.

No "quarto evento de cor: paleta fixa”, a complementação cromática acontece a partir das variáveis de análise cromática nela sugeridas por objetos que indicam para um intervalo extremamente restrito ou até para um único matiz, variando somente os parâmetros que dizem respeito aos cinzas da imagem (croma e valor). Chamamos objeto fixo o tipo de objeto reconhecido que indica matiz único, como por exemplo objetos institucionais (placas de trânsito, semáforos), com os quais temos contato exaustivo no cotidiano, tipos específicos de roupas e acessórios ou ainda os objetos construídos cromaticamente pela propaganda, como as cores agregadas aos produtos de grandes marcas (o vermelho da coca-cola). Quando este tipo de objeto é reconhecido numa imagem fotográfica em $\mathrm{p} / \mathrm{b}$, a falta da cor é percebida e o comparamos inconscientemente à interpretação anterior deste objeto, a partir da memória pessoal. O matiz sugerido na comparação será único e a complementação cromática a partir dele terá variações apenas nos eixos da luminosidade (valor) ou saturação (croma), de acordo com o que é sugerido na própria imagem.

$\mathrm{O}$ “quinto evento de cor: paleta cênica” é o ato da percepção cromática a partir de um tipo de estímulo, que diz respeito ao cenário que envolve os objetos numa cena. Este estímulo provoca a complementação cromática baseada na construção de uma paleta restrita às cores reservadas aos objetos, que estão guardados na memória. O matiz é dado pelo objeto reconhecido 
na imagem, que no caso da paleta cênica, chamaremos objeto cênico. Tais objetos são, por exemplo, céu, mar, folhagens, montanhas, nuvens, lagos, rios, cachoeiras, prédios, monumentos, areia da praia, paredes, assoalhos, etc., e acontecerão de acordo com um pequeno intervalo de matizes vizinhos e uma grande variação na luminosidade (valor) e saturação (croma).

O objeto que é reconhecido na imagem fotográfica em $\mathrm{p} / \mathrm{b}$ no "sexto evento de cor: paleta temporal" é um objeto especial dentre os que podem ser reconhecidos nos outros eventos, que traz componentes cromáticos temporais agregados, isto é, a paleta de cores para sua complementação cromática é formada a partir de matizes relacionados à época em que localizamos tal objeto. Objetos com características cromáticas temporais são guardados na memória, juntamente com a paleta relacionada à sua época, que é outro significado a ele agregado. Esta paleta é formada perceptivelmente, através de imagens resgatadas ou forjadas do passado, em filmes, televisão, fotografias, artes plásticas, cor da moda, maquiagem, etc. Não é preciso ter vivenciado as épocas determinadas para que se tenha uma paleta relacionada a elas na memória. Basta que se vivencie épocas determinadas em outros meios visuais, como os já mencionados cinema, televisão, vídeo, que por sua vez se baseiam em guias de cores para montar visualmente uma determinada época.

Chamaremos o estímulo vindo da imagem em $\mathrm{p} / \mathrm{b}$ no sexto evento de cor de objeto temporal. Mais precisamente, no âmbito dos parâmetros sugeridos pela imagem, os objetos reconhecidos são do tipo que apontam para um intervalo cromático relacionado à paleta de determinada época, o que faz o matiz dependente da ligação específica a uma característica temporal. São exemplos deste tipo de objeto: roupas, sapatos, acessórios e maquiagem da moda, carros, vestimentas de crianças, design dos acessórios de uma casa, eletrodomésticos, talheres, pratos, cafeteiras. A percepção reside no diferencial entre a roupa, por exemplo, que percebo na imagem fotográfica e as roupas que conheço atualmente. Todos esses objetos devem trazer a lembrança de outra época, principalmente no seu design.

$\mathrm{O}$ valor e o croma estão, assim como o matiz, relacionados à paleta da mesma época determinada e a variação de luminosidades (valor) e saturação (croma) corresponde àquela representada nesta mesma paleta. 
Sendo assim, a complementação cromática no âmbito do sexto evento de cor acontecerá dentro de um intervalo cromático restrito a uma determinada paleta representativa da época pela qual o objeto temporal esteja ligado.

O "sétimo evento de cor: paleta movediça" diz respeito ao ato da percepção cromática a partir do reconhecimento de objetos chamados movediços, e a formação perceptiva de uma paleta correspondente para a sua complementação cromática. Estes objetos não possuem formas familiares, convencionais e não remetem a algum significado cromático guardado na memória. Ao contrário dos outros eventos, onde o disparador do processo (estímulo) de percepção cromática é o reconhecimento de um determinado objeto e a comparação com a imagem guardada anteriormente na memória, no sétimo evento de cor há o reconhecimento de um objeto que não possui significado cromático específico agregado ou ainda não se reconhece um contexto para ele. Haverá então a comparação entre a luminosidade (valor) dada pela imagem e a luminosidade de cada cor-pigmento alocadas na memória.

No sétimo evento de cor, a construção da paleta para a complementação cromática do objeto movediço se dará então na associação dos cinzas da imagem, que são, na verdade, sugestões de luminosidades, com o coeficiente de claridade de cada cor-pigmento. A maior ou menor luminosidade das cores é perceptível pela retina, e o coeficiente de claridade passa a ser um significado agregado. Por isso também estão alocados na memória juntamente com as cores. Essa luminosidade corresponde à variável de análise cromática de Munsell "valor". A partir daí, haverá a comparação entre a luminosidade dada pelo "valor" sugerido pelo objeto movediço e a luminosidade das cores na memória. Desta comparação temos a segunda e a terceira variáveis de análise cromática, "matiz" e "croma".

O "oitavo e o nono eventos de cor: contraste simultâneo e sucessivo" mantêm uma relação com o conceito de complementação cromática diferenciada dos outros. Do quarto ao sétimo eventos de cor, a complementação cromática foi fundamento do próprio evento. Agora, a partir do oitavo evento de cor, ela é o estímulo fisiológico subjetivo para a ocorrência dos contrastes simultâneos na imagem fotográfica em p/b. 
Nos três primeiros eventos de cor abordados no item anterior, o enfoque se deu no estímulo fisiológico mecânico, causado por excitação mecânica, o que depende diretamente da retina. $\mathrm{O}$ oitavo e nono eventos de cor são os efeitos do estímulo fisiológico subjetivo, a partir da complementação cromática das imagens fotográficas em $\mathrm{p} / \mathrm{b}$. Este tipo de estímulo é gerado a partir de uma excitação subjetiva, ou seja, a cor aparece a partir de processos ocorridos na própria retina ou no cérebro.

O oitavo evento de cor são os contrastes simultâneos que ocorrem numa imagem fotográfica em $\mathrm{p} / \mathrm{b}$ a partir da paleta formada para o processo de complementação cromática do objeto. Porém, os contrastes simultâneos que ocorrem neste evento não se dão por estímulo objetivo, quer dizer, não há a resposta fisiológica da retina em relação a uma saturação. No caso do oitavo e nono eventos de cor, os efeitos da saturação da retina também são objetos guardados na memória anteriormente, num composto com a cor indutora, e aparecem juntamente com a complementação cromática do objeto reconhecido na imagem.

Michel-Eugène Chevreul (Pedrosa, 1982) definiu o contraste simultâneo das cores como sendo o fenômeno que se registra ao observarmos cores diferentes por recíproca influência. Mais especificamente, cores complementares aparecem no entorno da forma que guarda a cor pela qual a retina é saturada. Este fenômeno acontece também a partir de estímulo subjetivo. A memória, ao ser acionada na construção de paletas para a complementação cromática, estimula a retina e provoca o fenômeno dos contrastes simultâneos.

O oitavo evento de cor é a ocorrência do fenômeno do contraste simultâneo das cores por estímulo subjetivo, a partir dos objetos reconhecidos e complementados cromaticamente nas imagens fotográficas em $\mathrm{p} / \mathrm{b}$. Este evento depende primeiramente da ocorrência da complementação cromática. Sendo assim, retomaremos algumas das imagens já comentadas neste mesmo capítulo para em seguida apontar a ocorrência do oitavo evento de cor.

O nono evento de cor são os contrastes sucessivos e mistos que ocorrem a partir de uma imagem fotográfica em $\mathrm{p} / \mathrm{b}$, onde ocorreu a formação da paleta para o processo de complementação cromática do objeto. 


\section{SIMULTANEIDADE E MUTABILIDADE}

Nos itens anteriores descrevo os nove eventos de cor de forma individual e exclusiva. Cabe neste momento construir uma análise em torno da presença simultânea e da mutabilidade desses eventos, com o objetivo de mostrar a sua interação numa mesma imagem fotográfica em preto-ebranco.

No âmbito de uma visão dinâmica da teoria da cor, que resgata os aspectos psicológicos e culturais da percepção cromática, colocando-os em igualdade de importância com os aspectos físicos e fisiológicos, pode-se falar da interação entre os eventos de cor em dois momentos:

1. Presença simultânea dos eventos de cor numa mesma imagem em preto-e-branco. A ocorrência dos eventos de cor não é linear, exclusiva e estanque como foi apresentada até aqui, mas sim simultânea. Eles aparecem numa mesma imagem, misturando-se uns aos outros ou se colocando uns em decorrência de outros. Deve-se ressaltar que a simultaneidade dos eventos de cor não é absoluta, isto é, não se apresentam simultaneamente todos os eventos numa mesma imagem, mas sim de acordo com os seus apelos visuais. Alguns eventos sempre estarão presentes nas imagens, enquanto outros serão percebidos muito raramente. Alguns serão facilmente perceptíveis, enquanto outros manterão certa dificuldade de percepção.

2. Mutabilidade na identidade dos objetos reconhecidos, o que acontece a partir da variação nas características pessoais de percepção dos indivíduos. Os objetos reconhecidos numa imagem fotográfica em pretoe-branco como fixos, cênicos, temporais ou movediços, podem apresentar mutabilidade em suas identidades, conforme visões perceptivas diferentes. Por exemplo, o que é objeto fixo (quarto evento de cor: paleta fixa) para um indivíduo, poderá ser objeto cênico (quinto evento de cor: paleta cênica) para outro. Os objetos reconhecidos numa imagem podem ainda sofrer mutabilidade na visão perceptiva de um mesmo indivíduo, isto é, um objeto poderá ser reconhecido como fixo e cênico simultaneamente, para a mesma pessoa.

Não é possível esgotar a presença dos vários eventos de cor numa imagem fotográfica em preto-e-branco, justamente pelo seu caráter complexo de percepção visual cromática. Mostrando as características 
de simultaneidade e mutabilidade dos eventos de cor, estaremos apenas mostrando uma pequena parte da sua complexidade e não esgotando as possibilidades.

\section{A COR NA FOTOGRAFIA: UMA MANIFESTAÇÃO CULTURAL}

Os estudos realizados, tanto por artistas quanto por cientistas, no campo da percepção visual cromática, concluíram que o ato de "ver" implica em algo muito mais complexo que a simples somatória de partes, tais como a natureza da luz, a relação química entre a cor e o objeto ou os aparelhos fisiológicos responsáveis pela percepção visual. Sabendo que a percepção visual humana é construída também com base cultural, a influência de suas discussões na formação evolutiva de nossa percepção cromática é uma evidência.

A evolução dos estudos no âmbito da teoria da cor apontam para uma interação perceptiva complexa, considerando a relação que os indivíduos mantêm com a cor não como pura observação, mas principalmente como um ato criativo.

Através dos aspectos físicos e fisiológicos da cor, concluímos que a noção da diferença ou contraste entre as cores é a sua base de informação, isto é, dentro da coerência de um sistema, a informação cromática é obtida através do contraste entre as cores. Isto quer dizer que as noções de significação dos objetos não podem mais estar associadas somente às decisões do observador, mas também à configuração do mundo visível real. Levando estas questões ao nosso problema, concluímos que na observação de uma imagem fotográfica em preto-e-branco, a complementação cromática é provocada principalmente pela noção de diferença entre os cinzas da imagem e os objetos guardados na memória e não somente pela associação consciente entre a suposta falta da cor e sua característica cromática correspondente.

Juntamente com as teorias de Kandinsky (1991), Gerstner (1988) e Itten (1992) sobre a ligação entre uma cor e uma determinada forma, outros conceitos como a constância cromática e a cor de memória nos levaram à conclusão de que, ao observarmos uma imagem em preto-e- 
branco, temos momentos de criação advindos da correlação entre o objeto reconhecido e sua cor alocados na memória.

Os estudiosos dos aspectos psicológicos destacados a partir da teoria da cor, como J. J. Gibson (1974), confirmam que a percepção agrega as características sensórias dos objetos e, de alguma forma, não conseguimos desagregá-las. O conceito de que a cor não pode ser percebida de forma isolada do objeto nos levou a concluir que existe a complementação cromática dos objetos que reconhecemos numa imagem fotográfica em preto-e-branco, no sentido de, perceptivelmente, não conseguirmos isolálo da sua cor.

No capítulo 2, vimos alguns aspectos da imagem fotográfica, recorte necessário no universo das imagens em preto-e-branco.

A fotografia em preto-e-branco é vista de uma maneira especial por supostamente não ter as cores do mundo visível real. Quando uma fotografia em preto-e-branco é observada, as texturas e formas dos objetos são mais facilmente percebidas, tornando-se "chaves" perceptivas para a memória da sua cor .

Entendendo o processo de complementação cromática, podemos concluir também que as cores complementadas na fotografia em preto-ebranco são mais luminosas do que as cores do mundo físico real, pois se tratam de cores de contraste, dando às imagens fotográficas em preto-ebranco a condição de possuir um colorido mais intenso e profundamente relacionado à percepção intuitiva e criativa dos seres humanos.

Diante dessas questões discorridas durante todo o texto, é inevitável afirmar que este trabalho envolveu um estudo sobre a dilatação dos limites da percepção cromática humana, que se dá também no domínio do psicológico, do cultural e do social.

Segundo Geertz (1997), a capacidade de uma imagem de fazer sentido é um produto da experiência coletiva. Se considerarmos a fotografia como um sistema particular de formas simbólicas, teremos que levar em consideração, com Geertz, que este sistema particular só faz sentido através da sua participação no sistema geral que chamamos cultura. Neste sentido, os eventos de cor são elementos fundadores de um novo modo de perceber as imagens fotográficas em preto-e-branco, envolvendo mais a 
complexidade da percepção do que a simples sensação cromática. Como os eventos são atos de perceber a cor flagrados na imagem fotográfica em preto-e-branco, confirmam a dilatação evolutiva da percepção visual. Temos agora que considerar a imagem fotográfica "atravessada" por diversos atos de percepção cromática (os eventos), que interagem simultaneamente. Por isso, a observação de uma imagem fotográfica em preto-e-branco deve ser considerada como criativa e única.

Há muito tempo é conhecida a forma como reconhecemos os objetos em uma imagem (assim mostram os estudos de Arnheim (1986)), ou como as texturas estão ligadas ao material deste objeto ou como são notados os "brilhos metálicos" da cor (confirmados nas experiências de Edwin Land [1977]), porém sempre estudados isoladamente. O primeiro evento de cor descreve uma situação onde estes conceitos acontecem ao mesmo tempo, ressaltando principalmente a relação entre eles na observação da fotografia em preto-e-branco.

Também as mutações cromáticas foram exaustivamente estudadas desde o século XIX por Chevreul (1839), porém sem integrá-las aos fatos perceptivos como um todo complexo. No segundo evento de cor, as mutações cromáticas são exemplificadas na percepção visual das imagens em preto-e-branco, integrando-as às outras características dos objetos reconhecidos neste tipo de imagem.

A imagem fotográfica em preto-e-branco não tinha sido pensada como uma reunião de anteparos perfeitos para a ocorrência do fenômeno da cor inexistente antes do terceiro evento de cor. Este fenômeno era também estudado isoladamente, exemplificando fenômenos com as radiações monocromáticas pela física ou confirmando as mutações cromáticas na teoria da cor, como confirmam os estudos de Israel Pedrosa (1982).

Além disso, as relações entre a percepção visual cromática e os aspectos psicológicos, culturais e sociais eram também tratados teoricamente e sem aplicação prática, quando não em forma, pelo menos em áreas específicas.

A psicologia e a antropologia sabiam, através de pesquisadores como J. J. Gibson (1974) e Alfred Lang (1997), desde muito tempo, que os objetos são guardados na memória juntamente com a sua cor, e que a percepção cromática estaria inevitavelmente agregada à percepção 
de todas as outras características perceptíveis deste objeto, de maneira a impossibilitar a percepção isolada de cada uma dessas características. Estudos em torno do fenômeno da constância cromática e da cor de memória também confirmaram que percebemos os objetos num todo, juntamente com a sua cor.

A complementação cromática do objeto fixo (quarto evento de cor), do objeto cênico (quinto evento de cor), do objeto temporal (sexto evento de cor) e do objeto movediço (sétimo evento de cor) é a reunião dos mesmos conceitos de percepção cromática da psicologia e antropologia, flagrados no âmbito da observação e percepção visual de uma imagem fotográfica em preto-e-branco.

O estímulo subjetivo para a percepção cromática é bastante estudado nas áreas da neurologia, neuro-oftalmologia e também da psicologia, nas pesquisas de Oliver Sacks (1995), Semir Zeki (1990) e E. Thompson (1992). Casos de acromatopsia cerebral adquirida têm sido considerados como uma prova de que a percepção visual cromática, assim como toda percepção vinda dos sentidos, não está localizada numa única região delimitada do cérebro humano, mas ao contrário, que mantém relação estreita com as áreas determinadas à linguagem e à motricidade, por exemplo. $\mathrm{O}$ oitavo e nono eventos de cor aplicam essas pesquisas e conclusões no ato perceptivo cromático da geração de contrastes a partir da complementação cromática dos objetos reconhecidos na imagem fotográfica em preto-ebranco.

Enfim, os eventos de cor na fotografia em preto-e-branco mostraram os aspectos discutidos isoladamente nas diversas áreas do conhecimento humano em interação criativa. Por isso, são um sinal de dilatação da percepção visual, em termos evolutivos.

Enfim, a imagem fotográfica em preto-e-branco deve ser considerada além do simples rótulo de imagem "sem cor". A complexidade da percepção visual cromática do ser humano atravessa a simples consideração da falta da cor numa imagem fotográfica em preto-e-branco e mostra as possibilidades da complementação cromática dos seus objetos, quando reconhecidos e comparados às informações anteriormente retidas na memória. A cor 
não pertence fisicamente ao objeto, mas pertence perceptivamente e culturalmente a este objeto. Por isso, ao reconhecermos um objeto numa imagem fotográfica em preto-e-branco, vamos complementá-lo com a cor perceptiva e cultural, a partir da sua presença física.

\section{REFERÊNCIAS}

ARNHEIM, R. Arte e Percepção Visual. São Paulo: Pioneira, 1986.

BARTLESON, C. J. “Memory Colors of Familiar Objects”. In: Journal of the Optical Society of America, vol. 50, no. 1, JAN 1960.

CAIVANO, J. L. Sistemas de Ordem del Color. Buenos Aires: UBA, 1995.

CHEVREUL, M. "Les Lois du Contraste Simultané des Couleurs et l'assortiment des Object Colorés”. Paris: 1839.

DAMÁSIO A. et al. "Central Achromatopsia - Behavioral, anatomic, and physiologic aspects”. In: Neurology 30: (10): 1064 - 1071, 1980.

GERSTNER, K. “Las Formas del Color”. Madrid: Ed. Hermann Blume, 1988.

GEERTZ, C. O Saber Local. Petrópolis, RJ: Vozes, 1997.

GIBSON, J. J. "Perception of the Visual World" .Connecticut: Greenwood Press Publishers, 1974.

ITTEN, J. “The Art of Color”. New York, 1992.

JANSON, H. W. História da Arte. São Paulo: Martins Fontes, 1996.

KANDINSKY, W. Do Espiritual na Arte. Lisboa: Publicações Dom Quixote, 1991.

LAND, Edwin H. The retinex theory of Color Vision. In: Scientific American, dez 1977.

LANG, Alfred. "Non-Cartesian artifacts in dwelling activities: Steps towards a semiotic ecology”. In: Cole, M.; Engeström, Y.; Vasquez, O. (eds.) Mind, Culture, and Activity. USA: Cambridge University Press, 1997. 
PEDROSA, I. Da Cor à Cor Inexistente. Brasília: UnB, 1982.

SACKS, O. Um antropólogo em marte. São Paulo: Cia das Letras, 1995.

SILVEIRA, L. M. A Percepção da Cor na Imagem Fotográfica em Preto-e-Branco. Tese de Doutorado, PUC-SP: 2002.

THOMPSON, E.; PALACIOS, A.; VARELA, F. "Ways of Coloring: comparative color vision as a case study for a cognitive science". In: Behavioral and Brain Sciences. USA, 15: 1-74, 1992.

ZEKI, S. "A Century of Cerebral: Achromatopsia", In: Brain 113: 1721 - 1777, Part 6, DEC 1990. 
